\title{
„Zahnmedizin Report“ vergibt fünf Sterne an Nano-Hybrid-Komposit
}

„GrandioSO von VOCO ist ein sehr hochwertiges und universell einsetzbares $\mathrm{Na}$ no-Hybrid-Komposit mit sehr guten Verarbeitungs-Eigenschaften“ - so lautet das Urteil des wissenschaftlichen Informationsdienstes „Zahnmedizin Report“. 5 von 5 möglichen Sternen und damit die Note „Sehr gut" vergaben Zahnärztinnen und Zahnärzte nach einer 2-monatigen Testphase. Das Material eignet sich für Füllungen der Klassen I bis V, die Rekonstruktion traumatisch beschädigter Frontzähne, die Verblockung und Schienung von gelockerten Zähnen, Form- und Farbkorrekturen zur Verbesserung der Ästhetik, Kronenstumpfaufbauten und die Fertigung von Komposit-Inlays. Mit einem sehr hohen Füllstoffgehalt (89 Gew.\%), niedrigem Schrumpf (1,61\%) und einem dentinähnlichen E-Modul (16,65 GPa) ermöglicht das Material ebenso beständige wie ästhetische Restaurationen. Das Material ist

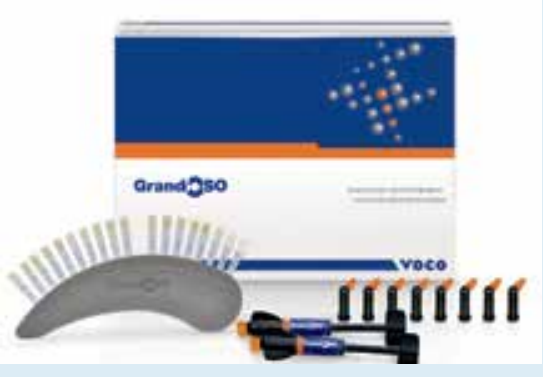

sehr gut zu polieren und aufgrund seiner überragenden Abrasionsbeständigkeit bleibt der Glanz dauerhaft bestehen. Mit 17 Farben einschließlich der Zusatzfarben GA3.25 und GA5 wird das zahnmedizinisch relevante Farbspektrum vollständig abgedeckt. Die vollständige Bewertung ist in der Ausgabe 12/2014 des „Zahnmedizin Report" nachzulesen.

Nach einer Pressemitteilung der vOCO GmbH, Cuxhaven

Internet: www.voco.de 